\title{
Febuxostat in the management of hyperuricemia and chronic gout: a review
}

\author{
Miao $\mathrm{Hu}$ \\ Brian Tomlinson \\ Division of Clinical Pharmacology, \\ Department of Medicine \\ and Therapeutics, The Chinese \\ University of Hong Kong, Prince \\ of Wales Hospital, Shatin, \\ New Territories, Hong Kong SAR, \\ China
}

\begin{abstract}
Febuxostat is a novel, potent, non-purine selective xanthine oxidase inhibitor, which in clinical trials demonstrated superior ability to lower and maintain serum urate levels below $6 \mathrm{mg} / \mathrm{dL}$ compared with conventionally used doses of allopurinol. Febuxostat was well tolerated in long term treatment in patients with hyperuricemia including those experiencing hypersensitity/intolerance to allopurinol. Dose adjustment appears unnecessary in patients with mild to moderate renal or liver insufficiency or advanced age. The most common adverse reactions reported were abnormal liver function tests, headache, and gastrointestinal symptoms, which were usually mild and transient. However, whether hepatotoxicity becomes a limitation in the use of febuxostat needs to be determined in further studies. An increased frequency of gout flares occurs for a prolonged period after treatment initiation, as with any aggressive lowering of serum urate, and prolonged prophylaxis with colchicine or NSAIDs is usually required. Febuxostat has been granted marketing authorization by the European Commission in early 2008 for the treatment of chronic hyperuricemia and gout. Febuxostat is the first major treatment alternative for gout in more than 40 years and is a promising alternative to allopurinol, although continued long-term surveillance on safety and efficacy is required.
\end{abstract}

Keywords: febuxostat, TEI-6720, TMX-67, gout, hyperuricemia, xanthine oxidase inhibitor

\section{Introduction}

Gout occurs as an acute arthritis that appears when there is a sudden onset of inflammation in response to the accumulation of crystals of monosodium urate in or around a joint (Schlesinger 2004), which is closely associated with hyperuricemia. With persistent urate crystal deposition, gout may progress from acute episodic attacks to a disabling chronic deforming arthropathy, with destructive deposits of urate crystals (tophi) in bones, joints, subcutaneous tissue, and other organs (Becker 1988; Becker et al 2005b; Tomlinson 2005). Renal damage may occur due to interstitial urate crystal deposition and urinary tract stones composed entirely or partly of monosodium urate and uric acid crystals (Becker 1988; Schlesinger 2004).

The development of gout can be divided into four stages: asymptomatic hyperuricemia, the gouty attack, the intercritical period, and chronic gouty arthritis. It has been recognized that hyperuricemia may exist for many years before the first clinical attack of gout (Falasca 2006). Hyperuricemia has been thought to be the fundamental pathogenic biochemical aberration upon which various etiological factors predispose to the expression of the clinical disorder of gout (Teng et al 2006). Moreover, hyperuricemia is also associated with chronic renal damage (Iseki et al 2004), some metabolic disturbances and risk factors for atherosclerotic cardiovascular disease including hypertension, overweight, insulin resistance, and hyperlipidemia (Slot 1994), which may occur together as the metabolic syndrome. This may explain the recognized association between gout and cardiovascular disease (Abbott et al 1988; Krishnan et al 2006; Choi and Curhan 2007), although there are no studies to show 
whether lowering plasma urate will reduce the cardiovascular risk in humans (Kim et al 2003; Wortmann 2005).

Multiple epidemiological studies from a diverse range of countries suggest that gout has increased in prevalence and incidence in the past few decades and the profile of clinical gout is becoming more complex (Roddy et al 2007). The established risk factors for gout include genetic factors, excess alcohol consumption, purine-rich diet, metabolic syndrome, use of diuretics, and chronic renal failure (Roddy et al 2007). Trends in lifestyle and dietary factors may partly explain the changes in the epidemiology of gout (Hak and Choi 2008). Furthermore, suboptimal management also contributes to the rising prevalence of clinically symptomatic chronic gout (Roddy et al 2007).

Conventional dietary recommendations for gout have emphasized the restriction of purine intake. There are two main approaches: the traditional low purine, low protein, alcohol-restricted diet, and more recently, a weight-reducing, purine-unlimited, calorie- and carbohydrate-restricted diet, with increased proportional intake of both protein and unsaturated fats. However, a rigid purine restricted diet is of dubious therapeutic value and there are also no long-term studies of the efficacy of either approach (Fam 2002).

The treatment for an acute attack of gout is usually either colchicine or nonsteroidal anti-inflammatory drugs (NSAIDs). For chronic gout, prophylactic therapy to reduce the serum urate level is thought to be appropriate in patients who have more than two gout flares a year or in individuals with gouty complications, and this could reduce the likelihood of recurrent gout by $80 \%$ (Emmerson 1996; Choi et al 2005; Bruce 2006). The physiochemical properties of monosodium urate cause crystals to precipitate in body fluids if the concentration is greater than $6.8 \mathrm{mg} / \mathrm{dL}$ ( $400 \mu \mathrm{mol} / \mathrm{L})$. Hence the target of urate lowering therapy is to reduce the serum urate concentration to below $6.0 \mathrm{mg} / \mathrm{dL}(353 \mu \mathrm{mol} / \mathrm{L})$, which should prevent the recurrence of gouty attacks or at least reduce their frequency substantially and allow the remission in size of gouty tophi (Wortmann 2005).

It was previously considered that it may be useful to divide subjects with hyperuricemia into those who are urate overproducers from those who are underexcreters, based on the 24-hour uric acid excretion (Wortmann 2002). Underexcreters may be candidates for uricosuric drugs such as probenecid or benzbromarone, but probenecid has limited efficacy and/or safety in patients with renal impairment or prior urolithiasis, and the more potent uricosuric agent benzbromarone was associated with several cases of fulminant hepatic failure and is not generally available (Emmerson 1996; Li-Yu et al 2001; Becker et al 2005b).

The urate-lowering therapy allopurinol, a xanthine oxidase (XO) inhibitor, has been the mainstay of prophylactic treatment for gout and conditions associated with hyperuricemia for many years (Wortmann 2002). It is the treatment of choice for urate overproducers, tophaceous gout, nephrolithiasis, or urate nephropathy, and in patients with renal insufficiency (Teng et al 2006). In theory allopurinol should be effective in almost every patient with hyperuricemia if a sufficient dose is taken, but achieving normal serum urate levels may be difficult in patients with impaired renal function or in transplant recipients (Schlesinger 2004). In practice approximately $20 \%$ of patients report side effects with allopurinol and 5\% discontinue medication (Wortmann 2005). There is a rare but serious hypersensitivity reaction to allopurinol, which involves fever, rash, eosinophilia, hepatitis, and progressive renal insufficiency (Schlesinger 2004; Wortmann 2005). This appears to be dose- or plasma concentration-dependent and can cause up to $20 \%$ mortality (Teng et al 2006). Patients with renal insufficiency or receiving diuretic therapy are at increased risk of adverse effects (Wortmann 2005). It has been found that severe cutaneous adverse reactions, which include the drug hypersensitivity syndrome, Stevens-Johnson syndrome, and toxic epidermal necrolysis are strongly associated with the HLA-B*5801 allele in Han Chinese patients, which could be developed as a screening test to identify the risk before commencing therapy (Hung et al 2005). As a result of frequent failure to reach target serum urate levels, or the intolerance to allopurinol in some patients, the development of an alternative potent serum urate lowering treatment has been a desirable goal. Febuxostat is a novel potent selective inhibitor of $\mathrm{XO}$ that appears to be well tolerated in all groups of patients, including those who are sensitive to allopurinol.

\section{Pharmacology}

Febuxostat, \{TEI-6720, TMX-67, 2-[3-cyano-4-(2-methylpropoxy) phenyl]-4-methyl- thiazole-5-carboxylic acid\}, is a non-purine compound with the empiric chemical formula $\mathrm{C}_{16} \mathrm{H}_{16} \mathrm{~N}_{2} \mathrm{O}_{3} \mathrm{~S}$ and molecular weight of 316.38 (Bruce 2006). It is a selective inhibitor of XO that has been developed for the treatment of hyperuricemia and gout, as it was found to have a potent inhibitory activity for $\mathrm{XO} /$ xanthine dehydrogenase (XDH) during evaluation of a range of newly synthesized molecules (Komoriya et al 1993). In humans, the xanthine oxidoreductase (XOR) enzyme catalyzes the last two steps in uric acid synthesis, the oxidation of hypoxanthine to xanthine 
and of xanthine to uric acid (hypoxanthine $\rightarrow$ xanthine $\rightarrow$ uric acid). Humans and the great apes lack the enzyme uricase which converts uric acid into allantoin (Osada et al 1993). Some non-enzymatic conversion of uric acid to allantoin does take place and the ratio of serum urate to allantoin has been considered as a potential marker of oxidative stress (Benzie et al 1999).

$\mathrm{XOR}$ is synthesized as $\mathrm{XDH}$, which in mammals can easily be converted to XO by oxidation of sulfhydryl residues or by proteolysis (Okamoto et al 2003). Febuxostat was shown to inhibit both the oxidized and reduced forms of XO, unlike allopurinol and oxypurinol, each of which binds only to one form of the enzyme (Okamoto et al 2003; Takano et al 2005). The molecular mechanism of inhibition of XO activity by febuxostat (Adenuric ${ }^{\circledR}$, Ipsen, Paris, France) is by high affinity binding to the enzyme in a molecular channel leading to the molybdenum-pterin active site, whereas allopurinol exerts relatively weak competitive inhibition on activity of only the oxidized form of XO (Okamoto et al 2003; Takano et al 2005). In contrast to allopurinol and oxypurinol, febuxostat does not structurally resemble purines or pyrimidines and has no significant effect on the activities of other enzymes involved in purine and pyrimindine metabolism, which might relate to some of the adverse effects caused by allopurinol and its metabolites (Takano et al 2005).

More recently, Okamoto and Nishino have reported that XOR inhibitors can be categorized into different types according to the crystal structure of the various inhibitors binding to XOR (Okamoto and Nishino 2008). Febuxostat has numerous hydrogen bonds, salt bridges, and hydrophobic interactions with amino acids in the active site and almost completely fills the narrow channel leading to the molybdenum center of the enzyme, which is considered as a structure-based inhibitor, whereas allopurinol and oxypurinol are thought to be mechanism-based inhibitors (Okamoto and Nishino 2008). The XO inhibitory activity and hypouricemic effect of febuxostat compared to allopurinol have been studied in vitro and in a variety of animal models (Komoriya et al 1993; Osada et al 1993; Horiuchi et al 1999). All these studies demonstrated that febuxostat had a greater potency than allopurinol in reducing serum urate levels and/or allantoin levels. Furthermore, the pleiotropic effects of febuxostat dependent on its hypouricemic effect have also been investigated and these studies provided a foundation for later evaluations in humans (Sanchez-Lozada et al 2008a, b, c; Zhao et al 2008).

As increased fructose consumption is associated with hyperuricemia, the metabolic syndrome, and renal damage,
Sanchez-Lozada et al evaluated whether febuxostat could alleviate some of the features of the metabolic syndrome as well as the renal hemodynamic alterations and afferent arteriolopathy induced by a high-fructose diet in rats. They found that a high-fructose diet was associated with hyperuricemia, hypertension, as well as increased plasma triglycerides and insulin. Febuxostat treatment in rats on a high-fructose diet resulted in significant lowering of blood pressure, serum urate, triglycerides, and insulin ( $\mathrm{p}<0.05$ for all comparisons) compared with those without treatment, and it also significantly reduced glomerular pressure, renal vasoconstriction, and afferent arteriolar area relative to those without treatment. However, febuxostat treatment in rats on a normal diet had no significant effects (Sanchez-Lozada et al 2008a).

Considering the close association between prolonged hyperuricemia and renal disease, Sanchez-Lozada et al evaluated the effect of febuxostat on progressive renal disease in a 5/6 nephrectomy (5/6 Nx) model in Wistar rats with and without hyperuricemia induced by the uricase inhibitor oxonic acid (OA) (Sanchez-Lozada et al 2008b). The 5/6 Nx rats given OA and placebo developed hyperuricemia, renal vasoconstriction and glomerular hypertension in association with further aggravation of afferent arteriolopathy compared with those without OA-induced hyperuricemia. Febuxostat prevented OA-induced hyperuricemia and in 5/6 Nx rats with or without OA-induced hyperuricemia it ameliorated proteinuria, preserved renal function and prevented glomerular hypertension. Functional improvement was accompanied by preservation of afferent arteriolar morphology and reduced tubulointerstitial fibrosis. These results suggested that febuxostat prevented renal injury in 5/6 Nx rats with and without coexisting hyperuricemia and due to its effect on preserving preglomerular vessel morphology, normal glomerular pressure was maintained even in the presence of systemic hypertension (Sanchez-Lozada et al 2008b).

Using different animal models, the same group of researchers also examined the effect of febuxostat on hyperuricemia-induced hypertension and renal damage (Sanchez-Lozada et al 2008c). They found that in OA-induced hyperuricemic rats, febuxostat lowered uric acid and ameliorated systemic and glomerular hypertension as well as mesangial matrix expansion and the development of preglomerular arteriolar disease as indicated by a reduction of the arteriolar area and media-to-lumen ratio. In normal rats, febuxostat tended to lower uric acid but had no effect on blood pressure, renal hemodynamics, and afferent arteriole morphology. The authors suggested that febuxostat merits further evaluation 
for the treatment of hypertension and renal alterations induced by hyperuricemia (Sanchez-Lozada et al 2008c).

More recently, Zhao et al (2008) reported the effects of chronic XO inhibition by febuxostat or allopurinol on the progression of chronic heart failure (CHF) induced by left coronary artery ligation in rabbits, which have low intrinsic myocardial XO activity similar to humans. One day after coronary ligation, rabbits were assigned to early treatment with vehicle or febuxostat for 49 days or to delayed-treatment with vehicle for 21 days followed by either febuxostat or allopurinol for 28 days. Treatment with febuxostat initiated shortly after myocardial infarction delayed or prevented the onset of CHF, but XO inhibition with either drug initiated after establishment of the disease had no cardiac protection effects (Zhao et al 2008).

\section{Pharmacokinetics}

After oral administration, about $85 \%$ of febuxostat is absorbed rapidly with a time $\left(\mathrm{t}_{\max }\right)$ to reach peak plasma concentrations $\left(\mathrm{C}_{\max }\right)$ of approximately 1 hour in healthy human subjects (Bruce 2006). In a phase I study in which oral febuxostat doses of 40, 70, and $120 \mathrm{mg}$ were given to healthy male and female adults $(\mathrm{n}=154), \mathrm{C}_{\max }$ values of $1.53,3.08$, and 4.47 $\mu \mathrm{g} / \mathrm{mL}$ occurred at $\mathrm{t}_{\text {max }}$ of about 1 hour, with area under the plasma concentration-time curve (AUC) values of 4.00, 6.93, and $11.31 \mu \mathrm{g} \cdot \mathrm{h} / \mathrm{mL}$, respectively. The elimination half-life $\left(t_{1 / 2}\right)$ values tended to increase (from 3.8 to 9.1 hours) with increasing doses and were longer after multiple doses (6.3 to 11.9 hours) compared with single doses (Becker et al 2004a). Escalating dose pharmacokinetic studies of single and multiple doses of febuxostat in healthy volunteers have shown that $\mathrm{C}_{\max }$ and $\mathrm{AUC}$ exhibit an approximately linear relation with single doses of 10 to $240 \mathrm{mg}$ and 10 to $120 \mathrm{mg}$, respectively, and nearly dose proportional increases were noted for both $\mathrm{C}_{\text {max }}$ and AUC after multiple oral doses with a mean apparent total clearance of 10 to $12 \mathrm{~L} / \mathrm{h}$ and an apparent volume of distribution at steady state of 33 to $64 \mathrm{~L}$ (Becker et al 2004a; Khosravan et al 2006b). The AUC increased more than proportionally between the groups receiving 120 and 240 mg daily suggesting some enterohepatic recirculation (Becker et al 2004a; Khosravan et al 2006b) (Table 1).

Febuxostat is highly bound to albumin in blood ( 99\%) and appears to have a low to medium apparent volume of distribution at steady state of approximately $0.7 \mathrm{~L} / \mathrm{kg}$ (Mayer et al 2005). The metabolism of febuxostat occurs predominantly in the liver by glucuronidation to produce the acyl-glucuronide metabolite $(22 \%-44 \%$ of the dose), and to a much lesser extent $(2 \%-8 \%)$, to produce oxidative metabolites, 67M-1, 67M-2, and 67M-4 (Figure 1) by cytochrome P450 enzymes (Khosravan et al 2006b). Approximately $25 \%$ to $45 \%$ of the drug was excreted in urine mainly as the conjugate with only about $1 \%$ to $6 \%$ being eliminated as the unchanged drug. An additional $2 \%$ to $8 \%$ of the dose was excreted as oxidative metabolites, either unchanged or as conjugates. Age and gender did not have statistically or clinically significant effects on the pharmacokinetics, pharmacodynamics or safety of febuxostat in healthy individuals after daily oral dosing with febuxostat at $80 \mathrm{mg}$ for 7 days, which suggested that no dose adjustment should be necessary when administering febuxostat based on age or gender (Khosravan et al 2008b). Patients with gout and/or hyperuricemia treated
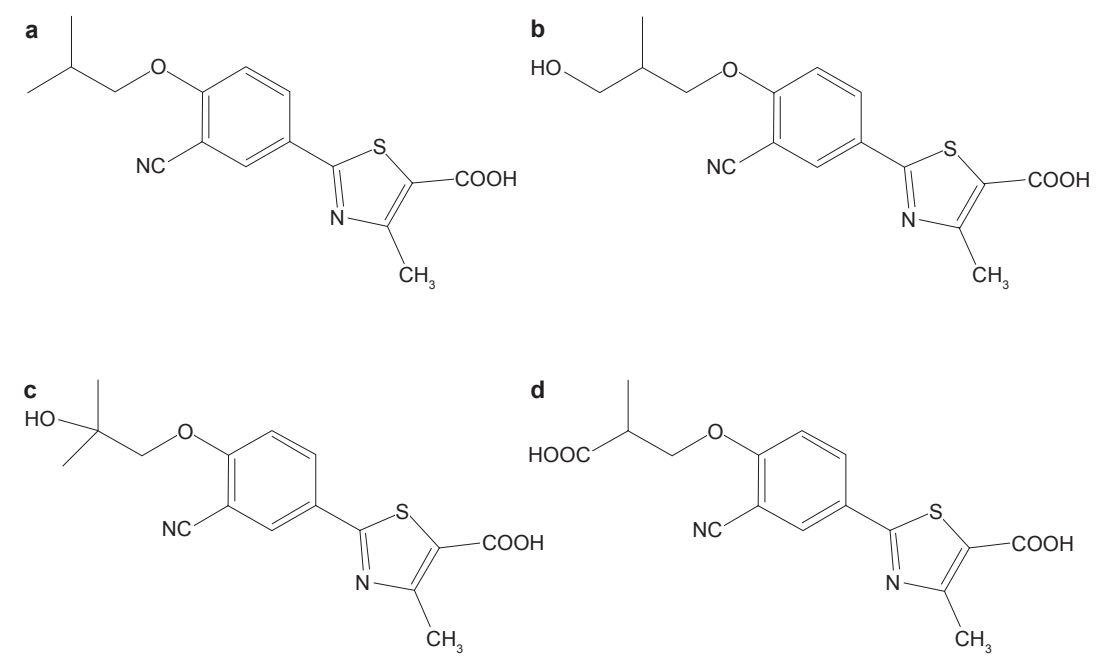

Figure I Chemical structures of (a) febuxostat and metabolites (b) 67M-I, (c) 67M-2, and (d) 67M-4. Adapted with permission from Khosravan R, Grabowski BA, Wu JT, et al. 2006b. Pharmacokinetics, pharmacodynamics and safety of febuxostat, a non-purine selective inhibitor of xanthine oxidase, in a dose escalation study in healthy subjects. Clin Pharmacokinet, 45:82I-4I. Copyright (c) 2006 Wolters Kluwer. 
with oral febuxostat at $10 \mathrm{mg}$ daily for 2 weeks, then $20 \mathrm{mg}$ daily for a further 4 weeks had similar AUC and $C_{\text {max }}$ values for febuxostat after the last dose as those reported for the same dose in healthy male adults (Komoriya et al 2003).

\section{Renal impairment}

Although renal clearance may only contribute to a small degree to the total systemic clearance of febuxostat, the effects of renal impairment on the pharmacokinetics and pharmacodynamics of febuxostat have been evaluated considering this is of clinical importance as many patients with gout may have impaired renal function. A clinical study was conducted to examine the pharmacokinetics and pharmacodynamics of febuxostat in individuals $(n=15)$ with mild (creatinine clearance $\left[\mathrm{Cl}_{\mathrm{cr}}\right] 50-80 \mathrm{~mL} / \mathrm{min}$ ) or moderate $\left(\mathrm{Cl}_{\mathrm{cr}} 30-50 \mathrm{~mL} / \mathrm{min}\right)$ impairment in renal function, compared with healthy $\left(\mathrm{Cl}_{\mathrm{cr}} \geq 80 \mathrm{~mL} / \mathrm{min}\right.$ ) participants (Hoshide et al 2004). The difference in plasma AUC for unchanged febuxostat after single oral doses of $20 \mathrm{mg}$ febuxostat was less than 2-fold across the groups, indicating that renal impairment had little clinical impact on the pharmacokinetic profile. Changes in plasma urate levels from pre-dose levels were not significant in this study (Hoshide et al 2004).

Another parallel-group, open-label, multiple-dose study compared the safety, pharmacokinetics, and pharmacodynamics of febuxostat $(80 \mathrm{mg} / \mathrm{d})$, administered orally for 7 days, in individuals with normal renal function $\left(\mathrm{Cl}_{\mathrm{cr}}>80 \mathrm{~mL} / \mathrm{min} / 1.73 \mathrm{~m} ; \mathrm{n}=11\right)$, or mild $\left(\mathrm{Cl}_{\mathrm{cr}} 50-80 \mathrm{~mL} /\right.$ $\min / 1.73 \mathrm{~m} ; \mathrm{n}=6)$, moderate $\left(\mathrm{Cl}_{\mathrm{cr}} 30-49 \mathrm{~mL} / \mathrm{min} / 1.73 \mathrm{~m}\right.$; $\mathrm{n}=7)$, or severe $\left(\mathrm{Cl}_{\mathrm{cr}} 10-29 \mathrm{~mL} / \mathrm{min} / 1.73 \mathrm{~m} ; \mathrm{n}=7\right)$ renal impairment. Mean unbound febuxostat $\mathrm{t}_{\max }$ and $\mathrm{C}_{\max }$ values in subjects with various degrees of renal impairment were similar to those in subjects with normal renal function, whereas the mean $\mathrm{AUC}_{(24 \mathrm{~h})}$ unbound and $\mathrm{t}_{1 / 2} \mathrm{z}\left(\mathrm{t}_{1 / 2}\right.$ obtained by a non-compartment analysis from the terminal slope of the concentration-time curve) values tended to increase with increasing renal impairment. For the $\mathrm{C}_{\max }$ and $\mathrm{AUC}_{(24 \mathrm{~h})}$ values for the quantifiable active metabolites $67 \mathrm{M}-1,67 \mathrm{M}-2$, and $67 \mathrm{M}-4$, with the exception of $\mathrm{C}_{\text {max }}$ for $67 \mathrm{M}-1$, regression analyses indicated a significant linear relationship with $\mathrm{Cl}_{\mathrm{cr}}$, suggesting that plasma exposure to the metabolites as well as febuxostat was generally increased in proportion to the degree of renal impairment. Although plasma exposure to febuxostat and its metabolites was generally higher in subjects with increasing degrees of renal impairment, the percentage reductions in serum urate were comparable, with a mean value of $55 \%$ to $64 \%$ by day 7 irrespective of renal function. The 80-mg once-daily dose of febuxostat was safe and well tolerated and the investigators concluded that no dose adjustment is required based on differences in renal function (Mayer et al 2005).

\section{Hepatic impairment}

As hepatic metabolism plays an important role in febuxostat elimination the effects of hepatic impairment on the pharmacokinetics, pharmacodynamics, and safety of febuxostat were investigated in a phase I study in individuals with normal ( $n=11$ ), mildly impaired (Child-Pugh class A; $n=8$ ) or moderately impaired (Child-Pugh class $\mathrm{B} ; \mathrm{n}=8$ ) hepatic function. Subjects took oral febuxostat $80 \mathrm{mg}$ daily for 7 days. There were smaller reductions in serum urate in the patients with hepatic impairment than in those with normal hepatic function but no differences in the pharmacokinetic parameters of febuxostat or its metabolites, suggesting the dosage may not need to be reduced in patients with mild or moderate hepatic dysfunction (Khosravan et al 2006a). However, the safety and efficacy of febuxostat in patients with severe hepatic impairment has not been studied. Liver toxicity was not reported in any of the animal studies.

\section{Drug interactions}

Febuxostat is highly bound to albumin in blood and is mainly metabolized by UDP-glucuronosyltransferase (UGT) 1 and 2 families and to a lesser extent by cytochrome P450 (CYP) enzymes. In vitro studies showed the presence of ibuprofen or warfarin did not change the plasma protein binding of febuxostat and febuxostat did not influence the plasma protein binding of ibuprofen or warfarin, suggesting that febuxostat was unlikely to cause a drug-drug interaction by displacement of protein binding (Mukoyoshi et al 2008). Examination of the inhibitory effect of febuxostat on CYP enzymes suggested that it had minimal inhibitory effect on the activities of any CYP (Mukoyoshi et al 2008). Based on the in vitro study that showed febuxostat had a weak inhibitory effect on CYP2D6, but no effect on CYP1A2, CYP2C9, CYP2C19 or CYP3A4, Khosravan et al (2005b) examined the effect of multiple doses of febuxostat $120 \mathrm{mg}$ daily on the pharmacokinetics of desipramine, a substrate for CYP2D6. A small increase in total exposure to desipramine was found suggesting that CYP2D6-mediated metabolism was mildly inhibited, but this was considered clinically insignificant (Khosravan et al $2005 b)$. The potential interactions between febuxostat and other medications which might be concurrently used in patients with hyperuricemia and gout have been evaluated in some studies.

Four phase I, two-period, crossover studies were performed in healthy male and female subjects to evaluate 
Table I Pharmacokinetics of febuxostat

\begin{tabular}{|c|c|c|c|}
\hline Reference & Subjects & Dose & Results \\
\hline $\begin{array}{l}\text { (Becker et al 2004a; } \\
\text { Khosravan et al 2006b) }\end{array}$ & $\begin{array}{l}\text { Male and female healthy } \\
\text { volunteers }(n=142)\end{array}$ & $\begin{array}{l}\text { Different doses (10,20,30, } \\
40,50,70,90,120,160,180, \\
\text { and } 240 \mathrm{mg}) \text { with } \\
12 \text { subjects each group } \\
\text { for } 2 \text { weeks }\end{array}$ & $\begin{array}{l}\text { A linear PK and dose-response (\% decrease in } s \cup A \text { ) } \\
\text { relationship for febuxostat dosages within the } \\
10-120 \mathrm{mg} \text { range }\end{array}$ \\
\hline (Komoriya et al 2004) & $\begin{array}{l}\text { Patients with gout } \\
\text { and/or hyperuricemia } \\
(\mathrm{n}=10)\end{array}$ & $\begin{array}{l}10 \mathrm{mg} \text { daily for } 2 \text { weeks } \\
\text { then } 20 \mathrm{mg} \text { daily for } \\
4 \text { weeks }\end{array}$ & $\begin{array}{l}\text { Oxidative metabolites } 67 \mathrm{M}-\mathrm{I}, 67 \mathrm{M}-2 \text {, and } 67 \mathrm{M}-4 \text { had } \\
\text { similar } \mathrm{C}_{\max } \text { and } \mathrm{t}_{\max } \text { as parent drug and } 40 \% \text { of drug } \\
\text { was excreted in urine as glucuronic acid conjugate } \\
67-\text { Glu. Data were similar to those reported in } \\
\text { healthy male adults }\end{array}$ \\
\hline (Hoshide et al 2004) & $\begin{array}{l}\text { Healthy subjects and } \\
\text { individuals with mild or } \\
\text { moderate impairment in } \\
\text { renal function }(n=15)\end{array}$ & Single dose of $20 \mathrm{mg}$ & $\begin{array}{l}\text { The difference in plasma AUC for unchanged } \\
\text { febuxostat across the groups was less than 2-fold } \\
\text { indicating that renal impairment had little clinical } \\
\text { impact on the PK of the drug. Changes in sUA levels } \\
\text { from pre-dose levels were not significant }\end{array}$ \\
\hline (Mayer et al 2005) & $\begin{array}{l}\text { Male and female } \\
\text { subjects with normal } \\
\text { renal function }(n=11) \\
\text { and with mild }(n=6) \text {, } \\
\text { moderate }(n=7) \text {, or } \\
\text { severe renal impairment } \\
(n=7)\end{array}$ & $80 \mathrm{mg}$ daily dose for 7 days & $\begin{array}{l}\text { Plasma exposure to febuxostat and its metabolites } \\
\text { was generally higher in subjects with increasing } \\
\text { degrees of renal impairment, but the \% decrease } \\
\text { in sUA were comparable regardless of the renal } \\
\text { function group. No dose adjustment needed for } \\
\text { febuxostat treatment based on differences in renal } \\
\text { function }\end{array}$ \\
\hline (Khosravan et al 2006a) & $\begin{array}{l}\text { Subjects with normal } \\
\text { hepatic function } \\
(n=I I) \text { and mild } \\
(n=8) \text { and moderate } \\
(n=8) \text { hepatic } \\
\text { impairment }\end{array}$ & $80 \mathrm{mg}$ daily dose for 7 days & $\begin{array}{l}\text { No statistically or clinically significant differences in } \\
\text { the plasma PK and PD parameters were observed } \\
\text { between subjects with mild or moderate hepatic } \\
\text { impairment and those with normal hepatic function. } \\
\text { No dose adjustment needed in subjects with mild to } \\
\text { moderate hepatic impairment }\end{array}$ \\
\hline (Khosravan et al 2006c) & $\begin{array}{l}\text { Male and female healthy } \\
\text { volunteers, study I } \\
(\mathrm{n}=26) \text {; study } 2 \\
(\mathrm{n}=24)\end{array}$ & $\begin{array}{l}\text { In study I, subjects received } \\
\text { febuxostat } 80 \mathrm{mg} \text { once } \\
\text { daily, indomethacin } 50 \mathrm{mg} \\
\text { twice daily, or both for } \\
5 \text { days. In study } 2 \text {, subjects } \\
\text { received febuxostat } 80 \mathrm{mg} \text {, } \\
\text { naproxen } 500 \mathrm{mg} \text { twice }\end{array}$ & $\begin{array}{l}\text { Febuxostat had no effect on the plasma PK of } \\
\text { indomethacin and naproxen. Indomethacin had no } \\
\text { effect on the plasma PK of febuxostat. Although } \\
\text { naproxen caused an increase in plasma exposure } \\
\text { to febuxostat, this increase is not expected to be } \\
\text { clinically significant }\end{array}$ \\
\hline
\end{tabular}

(Khosravan et al 2008a) Male and female healthy volunteers $(n=92)$
(Khosravan et al 2008b)
Healthy male and female subjects (aged 18-40 years or $\geq 65$ years) $(n=96)$ naproxen $500 \mathrm{mg}$ twice daily, or both for 7 days

Single $40 \mathrm{mg}(\mathrm{n}=24)$, or multiple $80 \mathrm{mg}(\mathrm{n}=24)$, or single $120 \mathrm{mg}(\mathrm{n}=20)$ in fasting and non-fasting conditions, or single $80 \mathrm{mg}$ $(n=24)$ doses alone or with antacid

$80 \mathrm{mg}$ daily dose for 7 days
Food caused a decrease in the rate and extent of absorption of febuxostat, but this decrease was not associated with a clinically significant change in febuxostat PD effect. Despite a decrease in the absorption rate of febuxostat, antacid had no effect on the extent of febuxostat absorption

Age or gender had no clinically significant effect on the PK, PD, or safety of febuxostat

Abbreviations: $A \cup C$, area under the plasma concentration-time curve; $P D$, pharmacodynamic; $P K$, pharmacokinetic; sUA, serum uric acid.

the effect of food and antacid on the pharmacokinetics and/or pharmacodynamics of febuxostat. Food decreased rate and extent of absorption of febuxostat, but this decrease was not associated with a clinically significant change in the pharmacodynamic effect. With antacid there was a decrease in the absorption rate of febuxostat, but no effect on the total extent of febuxostat absorption. These findings suggested that febuxostat can be taken with food or antacid without a significant effect on the response (Khosravan et al 2008a). 
Grabowski et al (2005) reported that a single dose of hydrochlorothiazide $50 \mathrm{mg}$ did not alter the pharmacokinetics of febuxostat, but caused a slightly higher serum uric acid concentration that was not considered to be clinically significant. Khosravan et al evaluated the potential drug interactions between febuxostat and other medication for treatment or prevention of acute gout attacks, including colchicine, indomethacin and naproxen (Khosravan et al 2005a, 2006c). Febuxostat had no effect on the plasma pharmacokinetics of colchicine, indomethacin, and naproxen and none of these medications had clinically significant effects on the pharmacokinetics of febuxostat. Therefore, based on the plasma pharmacokinetic data in healthy subjects, febuxostat can be administered with colchicine, indomethacin or naproxen with no dose adjustments.

\section{Safety and efficacy in clinical trials}

The in vitro and animal studies with febuxostat showed it was more potent than allopurinol in reducing serum urate levels without any major additional adverse effects (Tomlinson 2005). A series of clinical trials from phase I to phase III have been carried out to evaluate the safety and efficacy of febuxostat in humans (Table 2).

A phase I, multiple-dose, placebo-controlled, doseescalation study was conducted in healthy male and female adults in the United States with a majority of Caucasian

Table 2 Efficacy of febuxostat in phase III and long term clinical trials

\begin{tabular}{|c|c|c|c|c|}
\hline Reference & Patients & Study design & Treatment & Outcomes \\
\hline $\begin{array}{l}\text { (Kamatani et al } \\
\text { 2004) }\end{array}$ & 256 (Japanese) & $\begin{array}{l}\mathrm{R}, \mathrm{DB}, \mathrm{MC}, \\
8 \text { weeks }\end{array}$ & $\begin{array}{l}\text { FBX } 40 \text { mg, ALO } \\
100 \text { mg BD }\end{array}$ & $\begin{array}{l}82 \% \text { of patients in the FBX arm achieved } \\
\text { sUA levels of } \leq 6.0, \text { compared with } \\
69 \% \text { in the ALO arm }\end{array}$ \\
\hline $\begin{array}{l}\text { (Becker et al } \\
\text { 2005a) FACT }\end{array}$ & $\begin{array}{l}762(77 \% \\
\text { Caucasian) }\end{array}$ & $\begin{array}{l}\mathrm{R}, \mathrm{DB}, \mathrm{MC} \\
52 \text { weeks }\end{array}$ & $\begin{array}{l}\mathrm{FBX} 80 \mathrm{mg}, \mathrm{I} 20 \mathrm{mg}, \\
\text { ALO } 300 \mathrm{mg}\end{array}$ & $\begin{array}{l}53 \%, 62 \% \text {, and } 21 \% \text { of patients in FBX } \\
80 \mathrm{mg}, 120 \mathrm{mg} \text {, and ALO } 300 \mathrm{mg} \text { groups } \\
\text { achieved sUA }<6 \mathrm{mg} / \mathrm{dL} \text {, respectively } \\
\text { ( }<0.00 \mathrm{I} \text { for the comparison of each } \\
\text { febuxostat group with the allopurinol } \\
\text { group) The overall incidence of gout } \\
\text { flares was } 64 \% 70 \% \text {, and } 64 \% \text { for FBX } \\
80 \mathrm{mg} \text {, I } 20 \mathrm{mg} \text {, and ALO } 300 \mathrm{mg} \text { groups, } \\
\text { respectively }\end{array}$ \\
\hline $\begin{array}{l}\text { (Schumacher et al } \\
\text { 2005) APEX }\end{array}$ & $\begin{array}{l}1067(78 \% \\
\text { Caucasian) } \\
\text { including } 40 \\
\text { with moderately } \\
\text { impaired renal } \\
\text { function }\end{array}$ & $\begin{array}{l}\mathrm{R}, \mathrm{PC}, \\
28 \text { weeks }\end{array}$ & $\begin{array}{l}\text { Placebo, FBX } \\
80 \mathrm{mg}, 120 \mathrm{mg}, \\
240 \mathrm{mg}, \mathrm{ALO} \\
300 \mathrm{mg} / 100 \mathrm{mg} \\
\text { (depend on renal } \\
\text { function) }\end{array}$ & $\begin{array}{l}48 \%, 65 \%, 69 \%, 22 \% \text {, and } 0 \% \text { of patients } \\
\text { in FBX } 80 \mathrm{mg}, 120 \mathrm{mg}, 240 \mathrm{mg} \text {, ALO } \\
300 / 100 \mathrm{mg} \text {, and placebo groups } \\
\text { achieved sUA }<6 \mathrm{mg} / \mathrm{dL} \text { at each of the } \\
\text { last } 3 \text { visits, respectively ( } \mathrm{p}<0.05 \mathrm{for} \\
\text { all comparison between groups) and } \\
44 \%, 45 \%, 60 \%, 0 \%, 0 \% \text { for subjects with } \\
\text { moderate renal impairment for each } \\
\text { groups }\end{array}$ \\
\hline $\begin{array}{l}\text { (Wortmann et al } \\
\text { 2006) EXCEL }\end{array}$ & $\begin{array}{l}1086(79 \% \\
\text { Caucasian) }\end{array}$ & $\begin{array}{l}\mathrm{R}, \mathrm{OL}, \mathrm{LT}, \\
\text { (an extension } \\
\text { study of } \\
2 \text { phase III } \\
\text { trials above) }\end{array}$ & $\begin{array}{l}\text { FBX } 80 \mathrm{mg}, \text { I } 20 \mathrm{mg} \text {, } \\
240 \mathrm{mg}, \mathrm{ALO} \\
300 \mathrm{mg} / 100 \mathrm{mg} \\
\text { (depend on renal } \\
\text { function) }\end{array}$ & $\begin{array}{l}\text { The incidence of gout flares decreased } \\
\text { gradually from I.4, I.72, and I. } 49 \\
\text { fares per year in the Ist year to } 0.19 \text {, } \\
0.0 \text {, and } 0.1 \text { I flares per year in the } \\
3 \text { rd year for febuxostat } 80 \mathrm{mg}, 120 \mathrm{mg} \text {, } \\
\text { and allopurinol } 300 / 100 \mathrm{mg} \text { groups, } \\
\text { respectively }\end{array}$ \\
\hline $\begin{array}{l}\text { (Schumacher et al } \\
\text { 2006) FOCUS }\end{array}$ & $\begin{array}{l}\text { II } 6(85 \% \\
\text { Caucasian) } \\
\text { with } 6 \text { I subjects } \\
\text { on continued } \\
\text { treatment } \\
\text { with } \geq 48 \text { months }\end{array}$ & OL, LT & $\begin{array}{l}\text { FBX } 40 \mathrm{mg}, \\
80 \mathrm{mg}, 120 \mathrm{mg}\end{array}$ & $\begin{array}{l}\text { Across all doses, the proportion of } \\
\text { subjects with sUA }<6.0 \mathrm{mg} / \mathrm{dL} \text { were } \\
78 \%, 76 \%, 84 \% \text {, and } 90 \% \text { at year I, } 2,3 \text {, } \\
\text { and } 4 \text {, respectively. Overall incidence of } \\
\text { gout flares requiring treatment declined } \\
\text { markedly by } 2 \text { years and continued over } \\
4 \text { year of febuxostat treatment. After } \\
\text { the Ist year of stable dose, subjects, on } \\
\text { average, had }<\text { I gout flare/year }\end{array}$ \\
\hline
\end{tabular}

Abbreviations: ALO, allopurinol; DB, double blind; FBX, febuxostat; LT, long term; MC, multicenter; OL, open label; PC, placebo controlled; R, randomized; sUA, serum uric acid. 
subjects $(n=142)$ (Becker et al 2004a; Khosravan et al 2006b). Febuxostat was given orally for 2 weeks in daily doses in the range of 10 to $240 \mathrm{mg}$. Febuxostat resulted in significant decreases in serum and urinary urate concentrations and increases in serum and urinary xanthine concentrations. The percentage decreases in serum urate concentrations ranged from $27 \%$ to $76 \%$ (net change: $1.34-3.88 \mathrm{mg} / \mathrm{dL}$ ), which were proportional to dosage for 10 to $120 \mathrm{mg}$ doses but higher doses $(>120 \mathrm{mg})$ did not appear to have a greater effect. Percentage decreases in serum uric acid were $27 \%$, $35 \%, 37.5 \%, 40 \%, 47 \%, 50 \%, 60 \%, 69 \%, 70 \%, 72 \%$, and $76 \%$ for the $10,20,30,40,50,70,90,120,160,180$, and $240 \mathrm{mg}$ doses, respectively. Proportional increases in serum xanthine concentrations, decreases in urinary uric acid excretion, and increases in urinary xanthine and hypoxanthine excretion were also observed for doses of $10 \mathrm{mg}$ to $120 \mathrm{mg}$. Adverse events were mild or moderate and self-limited, but not uncommon. The incidence of adverse events tended to be higher with higher doses of febuxostat. No deaths or serious adverse events were observed (Khosravan et al 2006b).

Based on the results from the above phase I study, the doses for phase II studies were selected and tested in patients with gout. A phase II double-blind, placebo-controlled, multicenter study included 153 patients, aged 23 to 80 years, with gout and baseline serum urate $\geq 8.0 \mathrm{mg} / \mathrm{dL}$ (Becker et al 2005b). Subjects were randomized to febuxostat (40 mg, $80 \mathrm{mg}$, $120 \mathrm{mg}$ ) or placebo once daily for 28 days with colchicine (0.6 mg twice daily) prophylaxis for 14 days prior to and 14 days after randomization. The subjects achieving the primary outcome of serum urate $<6.0 \mathrm{mg} / \mathrm{dL}$ on day 28 , were $0 \%, 56 \%$, $76 \%$, and $94 \%$ for placebo, $40 \mathrm{mg}, 80 \mathrm{mg}$, and $120 \mathrm{mg}$ dose febuxostat groups, respectively ( $\mathrm{p}<0.001$ for each treatment group vs. placebo). Compared with baseline, decreases in serum urate at day 28 were $2 \%, 37 \%, 44 \%$, and $59 \%$ for placebo, 40-, 80-, and 120-mg dose groups, respectively ( $\mathrm{p}<0.001$ for each treatment group vs placebo). Gout flares occurred with similar frequency in the placebo (37\%) and $40 \mathrm{mg}$ febuxostat (35\%) groups and with increased frequency in the higher dosage febuxostat groups (43\% with $80 \mathrm{mg}$; 55\% with $120 \mathrm{mg}$ ). During colchicine prophylaxis, gout flares occurred less frequently $(8 \%-13 \%)$. Incidences of treatment-related adverse events were similar in the febuxostat and placebo groups (Becker et al 2005b).

A long-term, open-label extension of the above 4-week double-blind phase II study included 116 patients and 69 patients continued for at least 2 years (Schumacher et al 2004; Wortmann et al 2004). Subjects were initially given febuxostat $80 \mathrm{mg} /$ day with titration to either 40 or $120 \mathrm{mg}$ based on serum urate and adverse events, achieving a stable dose after 28 weeks. Colchicine (0.6 mg twice daily) prophylaxis was implemented during the initial phase of treatment. Most patients $(74 \%-81 \%)$ maintained serum urate levels of $<6.0 \mathrm{mg} / \mathrm{dL}$ throughout the study period. Any treatment-related adverse events were mild-to-moderate with the most common being diarrhea, headache, and abnormal liver function test results. No serious adverse event was considered to be related to febuxostat. Analysis of a small number of patients $(n=9)$ in this extension study with gouty tophi revealed that tophus volume increased in patients with serum urate $>6.0 \mathrm{mg} / \mathrm{dL}$ and decreased in patients with serum urate $<6.0 \mathrm{mg} / \mathrm{dL}$ (Becker et al 2004c). Febuxostat was also efficacious, safe and well tolerated in a subgroup of allopurinol-intolerant patients included in the trial extension $(\mathrm{n}=8)$ (Becker et al 2004b). More recently, the investigators further reported the data from 61 subjects with long-term treatment with febuxostat for at least 4 years (FOCUS) (Schumacher et al 2006). Across all doses, the proportion of subjects with serum urate $<6.0 \mathrm{mg} / \mathrm{dL}$ were $78 \%, 76 \%, 84 \%$, and $90 \%$ at year $1,2,3$, and 4 , respectively. The overall incidence of gout flares requiring treatment declined markedly by 2 years and continued over 4 years of febuxostat treatment. After the first year of stable dose, subjects, on average, had $<1$ gout flare per year. 26 subjects entered the study with a palpable tophus; 20 (77\%) of these subjects had no tophus detectable at the examinations during the study. The most common treatment-related adverse events for all febuxostat groups were diarrhea, gastrointestinal motility disorders, headache, abnormal liver function tests, and hyperlipidemia. This longest clinical study of febuxostat therapy to date showed that long-term treatment with febuxostat reducing and maintaining serum urate $<6.0 \mathrm{mg} / \mathrm{dL}$ was accompanied by beneficial clinical outcomes, including reduction in gout flares and tophus volume (Schumacher et al 2006). They also found that 4 years treatment with febuxostat was safe, effective, and well tolerated in 6 allopurinol-intolerant patients, and 3 subjects with tophi identified at the time of enrollment had disappearance of their tophi by the fourth year of febuxostat treatment (Becker et al 2006).

The Febuxostat versus Allopurinol Controlled Trial (FACT), a phase III, randomized, double-blind, 52-week, multicenter trial, compared the safety and efficacy of febuxostat with allopurinol in adult subjects with gout (Becker et al 2005a). A total of 762 patients with chronic gout and serum urate levels $\geq 8.0 \mathrm{mg} / \mathrm{dL}$ were randomized to receive once-daily doses of either 80 or $120 \mathrm{mg}$ febuxostat or $300 \mathrm{mg}$ allopurinol for 52 weeks and 760 received at 
least one dose of the study drug during the study period. Naproxen (250 mg twice daily) or colchicine ( $0.6 \mathrm{mg}$ once daily) was provided for gout flare prophylaxis during the 2 -week washout period and first 8 weeks of the study. The primary endpoint of serum urate $<6.0 \mathrm{mg} / \mathrm{dL}$ at all the last three measurements at monthly intervals up to 52 weeks was reached in $53 \%, 62 \%$, and $21 \%$ of the febuxostat $80 \mathrm{mg}$ and $120 \mathrm{mg}$ and allopurinol $300 \mathrm{mg}$ groups, respectively ( $p<0.001$ for the comparison of each febuxostat group with the allopurinol group). Although the incidence of gout flares gradually decreased with continued treatment, the overall incidence during weeks 9 through 52 was similar in all groups: $64 \%$ of patients receiving $80 \mathrm{mg}$ of febuxostat, $70 \%$ of those receiving $120 \mathrm{mg}$ of febuxostat, and $64 \%$ of those receiving allopurinol. The median reduction in tophus area was $83 \%$ and $66 \%$ in patients receiving $80 \mathrm{mg}$ or $120 \mathrm{mg}$ of febuxostat and $50 \%$ in those receiving allopurinol $(p>0.05)$. More patients in the high-dose febuxostat group than in the allopurinol group $(\mathrm{p}=0.003)$ or the low-dose febuxostat group discontinued the study. The investigators concluded that febuxostat $80 \mathrm{mg}$ or $120 \mathrm{mg}$ daily was more effective than allopurinol $300 \mathrm{mg}$ daily in reducing serum urate (Becker et al 2005a).

Another large phase III study, the APEX study, involving 1067 subjects (78\% Caucasians) with gout and serum urate levels $\geq 8.0 \mathrm{mg} / \mathrm{dL}$ compared the safety and efficacy of febuxostat to allopurinol and placebo (Schumacher et al 2005). This study included 40 subjects with moderately impaired renal function (serum creatinine 1.6 to $\leq 2.0 \mathrm{mg} / \mathrm{dL}$ ) and a high dose of febuxostat for safety evaluation. Subjects were randomized to receive placebo, febuxostat $80 \mathrm{mg}, 120 \mathrm{mg}$, or $240 \mathrm{mg}$ (safety dose) or allopurinol once daily in a 1:2:2:1:2 ratio for 28 weeks. No dose adjustments based on renal function were made in the febuxostat treatment groups, but subjects randomized to allopurinol received $300 \mathrm{mg} /$ day if serum creatinine was $\leq 1.5 \mathrm{mg} / \mathrm{dL}$ and $100 \mathrm{mg} /$ day for serum creatinine 1.6 to $\leq 2.0 \mathrm{mg} / \mathrm{dL}$. The primary endpoint of the proportion of subjects with serum urate $<6.0 \mathrm{mg} / \mathrm{dL}$ at each of the last 3 visits was achieved in 48\%,65\%,69\%,22\%, and $0 \%$ in febuxostat $80 \mathrm{mg}, 120 \mathrm{mg}, 240 \mathrm{mg}$, allopurinol $300 / 100 \mathrm{mg}$, and placebo groups, respectively ( $\mathrm{p}<0.05$ for the comparison of each febuxostat group with the allopurinol group and placebo group) and 44\%, 45\%, 60\%, $0 \%$, and $0 \%$, respectively, for subjects with moderate renal impairment for each group. After 28 weeks, 76\%, 87\%, $94 \%, 41 \%$, and $1 \%$ of patients in febuxostat $80 \mathrm{mg}, 120 \mathrm{mg}$, $240 \mathrm{mg}$, allopurinol 300/100 mg, and placebo groups had serum urate $<6.0 \mathrm{mg} / \mathrm{dL}$ ( $\mathrm{p}<0.05$ for the comparison of each febuxostat group with the allopurinol group and placebo group). Adverse events including liver function abnormalities, headache, nausea and vomiting, abdominal pain, and dizziness, were similar in incidences across treatment groups. There were no increases in adverse events in subjects with moderate renal insufficiency including those receiving febuxostat $240 \mathrm{mg}$ daily. These results suggested that febuxostat (80 mg, $120 \mathrm{mg}$, or $240 \mathrm{mg}$ ) demonstrated superior efficacy compared with placebo and allouprinol (300 or $100 \mathrm{mg}$ ) in reducing and maintaining serum urate $<6.0 \mathrm{mg} / \mathrm{dL}$. Febuxostat was generally safe and well tolerated at all doses (Schumacher et al 2005).

Clinical benefits of long-term urate-lowering therapy with febuxostat have been evaluated in the EXCEL trial, which is an extension study of 2 Phase III trials mentioned above (FACT and APEX) (Wortmann et al 2006). This long-term open-label study was designed to determine if subjects treated with febuxostat or allopurinol maintaining serum urate $<6.0 \mathrm{mg} / \mathrm{dL}$ was associated with reduction in gout flare frequency and tophus resolution. A total of 1086 subjects completing the above two phase III trials were enrolled. At the time of interim analysis, 75\% (815/1086) of subjects completed $\geq 16$ months in EXCEL; the durations of exposure to initial treatment were 492, 428, and 271 days, respectively, for febuxostat $80 \mathrm{mg}, 120 \mathrm{mg}$, and allopurinol 300/100 mg. The incidence of gout flares decreased gradually from 1.4, 1.72, 1.49 fares per year in the first year to $0.19,0.0$, and 0.11 flares per year in the third year for febuxostat $80 \mathrm{mg}, 120 \mathrm{mg}$, and allopurinol $300 / 100 \mathrm{mg}$ groups, respectively. The most common febuxostat treatment-related adverse events were abnormal liver function tests, headache, hypertension, diarrhea, and arthralgia/stiffness, whereas the most common treatmentrelated adverse events for allopurinol were abnormal liver function tests and rash (Wortmann et al 2006).

The effects of lower doses of febuxostat were evaluated in Japanese subjects compared to placebo or allopurinol in some studies (Kamatani et al 2003, 2004). A phase II, multicenter, double-blind study was conducted to assess the efficacy and safety of doses of febuxostat in 128 patients with gout or hyperuricemia (serum urate levels $\geq 8.0 \mathrm{mg} / \mathrm{dL}$ ). Participants were randomized to receive once-daily doses of placebo or febuxostat $(10 \mathrm{mg}, 20 \mathrm{mg}$, or $40 \mathrm{mg} ; \mathrm{n}=32$, per group). Patients assigned to the febuxostat groups were administered $10 \mathrm{mg}$ febuxostat for the first 2 weeks, followed by $10 \mathrm{mg}, 20 \mathrm{mg}$, or $40 \mathrm{mg}$ for a subsequent 6-week treatment period, while individuals assigned to the placebo group 
received placebo throughout the 8 -week trial. Serum urate levels of $<6.0 \mathrm{mg} / \mathrm{dL}$ were achieved in $0 \%, 22 \%, 31.5 \%$, and $41.9 \%$ of patients with placebo, $10 \mathrm{mg}, 20 \mathrm{mg}$, and $40 \mathrm{mg}$ febuxostat groups, respectively. There was no significant difference in response rate between gout and hyperuricemia patients or between urate overproducers or underexcreters. Febuxostat was safe and well tolerated at all doses (Kamatani et al 2003).

A further phase III study compared the safety and efficacy of febuxostat with allopurinol in 256 Japanese subjects with gout or hyperuricemia with serum urate levels $\geq 8.0 \mathrm{mg} / \mathrm{dL}$ (Kamatani et al 2004). In this randomized, multicenter, double-blind study, patients received either febuxostat (10 mg once daily) or allopurinol (100 mg once daily) for a 12-week introductory phase before doses were increased for a further 44 days of treatment with febuxostat (40 mg once daily) or allopurinol (100 mg twice daily). The decrease in serum urate levels after 8 weeks of treatment was significantly ( $\mathrm{p}<0.001$ ) greater in the febuxostat group $(40.5 \%)$, compared with the allopurinol group (33.9\%). Furthermore, $82 \%$ of patients in the febuxostat arm achieved serum urate levels of $\leq 6.0$, compared with $69 \%$ in the allopurinol arm $(\mathrm{p}<0.05)$. Adverse reactions were reported in $11 \%$ of patients in the allopurinol group and $8.6 \%$ in the febuxostat group. The majority of adverse events were transient and mild in severity (Kamatani et al 2004).

\section{Summary}

Febuxostat has been shown to be safe and effective in lowering serum urate according to the available clinical data. Doses of $80 \mathrm{mg}$ of febuxostat are more effective in lowering serum urate than doses of $300 \mathrm{mg}$ of allopurinol. Febuxostat has shown to be well tolerated in long term treatment in patients experiencing hypersensitity/intolerance to allopurinol.

Dose adjustment does not seem to be necessary in patients with mild to moderate renal/liver insufficiency or advanced age according to data from these particular groups of subjects. The most common adverse reactions reported were abnormal liver function tests, headache, and gastrointestinal symptoms, which were usually mild and transient. Hepatotoxicity was not a feature in the animal studies, but whether it becomes a limitation in the clinical use of febuxostat needs to be determined in further studies. As with other urate-lowering therapies, the rapid decrease in serum urate associated with initiation of treatment with febuxostat caused a number of patients to experience acute gout flares. This appeared to be more frequent with the more potent serum urate-lowering effects of higher doses of febuxostat, but this increased incidence of gout attacks tended to decline with ongoing treatment and could be attenuated with concomitant prophylaxis during the initiation of febuxostat therapy. In February 2008, $80 \mathrm{mg}$ and $120 \mathrm{mg}$ of febuxostat film-coated tablets (Adenuric ${ }^{\circledR}$ ) were granted marketing authorization by the European Commission for the treatment of chronic hyperuricemia in conditions in which urate deposition has already occurred (including a history or presence of tophus and/or gouty arthritis), which is the first major treatment alternative for gout in more than 40 years (CHMP 2008; Ipsen 2008). A concern on potential serious cardiovascular adverse events was noted in the European Commission statement, but this was not apparent in the published clinical trial reports.

In summary, febuxostat is a promising urate-lowering therapy as an alternative to allopurinol for the treatment of hyperuricemia and gout, although further observation on post-marketing safety and efficacy of long term treatment with febuxostat in patients with gout or hyperuricemia and with other complications is required.

\section{Disclosures}

The authors have no conflicts of interest to disclose.

\section{References}

Abbott RD, Brand FN, Kannel WB, et al. 1988. Gout and coronary heart disease: the Framingham Study. J Clin Epidemiol, 41:237-42.

Becker MA. 1988. Clinical aspects of monosodium urate monohydrate crystal deposition disease (gout). Rheum Dis Clin North Am, 14:377-94.

Becker MA, Kisicki J, Khosravan R, et al. 2004a. Febuxostat (TMX-67), a novel, non-purine, selective inhibitor of xanthine oxidase, is safe and decreases serum urate in healthy volunteers. Nucleosides Nucleotides Nucleic Acids, 23:1111-6.

Becker MA, Schumacher HR Jr. Wortmann RL, et al. 2005a. Febuxostat compared with allopurinol in patients with hyperuricemia and gout. N Engl J Med, 353:2450-61.

Becker MA, Schumacher HR, Jr. Wortmann RL, et al. 2006. Allopurinol intolerant patients treated with febuxostat for 4 years. $A C R / A R H P$ Annual Scientific Meeting.

Becker MA, Schumacher HR, Jr. Wortmann RL, et al. 2005b. Febuxostat, a novel nonpurine selective inhibitor of xanthine oxidase: a twenty-eight-day, multicenter, phase II, randomized, double-blind, placebo-controlled, dose-response clinical trial examining safety and efficacy in patients with gout. Arthritis Rheum, 52:916-23.

Becker MA, Schumacher R, Wortmann R, et al. 2004b. Febuxostat, a novel non-purine selective inhibitor of xanthine oxidase, therapy in allopurinol intolerant patients. Arthritis Rheum, 50:803/103.

Becker MA, Schumacher R, Wortmann R, et al. 2004c. Magnetic resonance imaging of gouty tophi during treatment with febuxostat, a non-purine selective inhibitor of xanthine oxidase. Arthritis Rheum, 50:802/103.

Benzie IF, Chung W, Tomlinson B. 1999. Simultaneous measurement of allantoin and urate in plasma: analytical evaluation and potential clinical application in oxidant:antioxidant balance studies. Clin Chem, 45:901-4.

Bruce SP. 2006. Febuxostat: a selective xanthine oxidase inhibitor for the treatment of hyperuricemia and gout. Ann Pharmacother, 40:2187-94. 
CHMP. 2008. Committee for medicinal products for human use summary of positive opinion for Adenuric [online]. 21 February 2008. URL: http://www.emea.europa.eu/pdfs/human/opinion/ Adenuric_8075108en.pdf.

Choi HK Curhan G. 2007. Independent impact of gout on mortality and risk for coronary heart disease. Circulation, 116:894-900.

Choi HK, Mount DB, Reginato AM. 2005. Pathogenesis of gout. Ann Intern Med, 143:499-516.

Emmerson BT. 1996. The management of gout. $N$ Engl J Med, $334: 445-51$.

Falasca GF. 2006. Metabolic diseases: gout. Clin Dermatol, 24:498-508.

Fam AG. 2002. Gout, diet, and the insulin resistance syndrome.J Rheumatol, 29:1350-5.

Grabowski BA, Khosravan R, Wu JT, et al. 2005. Effect of hydrochlorothiazide on pharmacokinetics and pharmacodynamics of febuxostat. Arthritis Rheum, 52:S103-4.

Hak AE, Choi HK. 2008. Lifestyle and gout. Curr Opin Rheumatol, 20:179-86

Horiuchi H, Ota M, Kobayashi M, et al. 1999. A comparative study on the hypouricemic activity and potency in renal xanthine calculus formation of two xanthine oxidase/xanthine dehydrogenase inhibitors: TEI-6720 and allopurinol in rats. Res Commun Mol Pathol Pharmacol, 104:307-19.

Hoshide S, Takahashi Y, Ishikawa T, et al. 2004. PK/PD and safety of a single dose of TMX-67 (febuxostat) in subjects with mild and moderate renal impairment. Nucleosides Nucleotides Nucleic Acids, 23:1117-8.

Hung SI, Chung WH, Liou LB, et al. 2005. HLA-B*5801 allele as a genetic marker for severe cutaneous adverse reactions caused by allopurinol. Proc Natl Acad Sci U S A, 102:4134-9.

Ipsen. 2008. Adenuric ${ }^{\circledR}$ (febuxostat) receives marketing authorisation in the European Union. Ipsen Press Release 5 May 2008 [online]. URL: http://www.ipsen.com/articles/investorrelations/ regulatedinformation/20080505_autorisation_adenuric_eu_10.pdf.

Iseki K, Ikemiya Y, Inoue T, et al. 2004. Significance of hyperuricemia as a risk factor for developing ESRD in a screened cohort. Am J Kidney Dis, 44:642-50.

Kamatani N, Fujimori S, Hada T, et al. 2003. Phase II dose-response clinical trial using febuxostat (TMX-67), a novel-type xanthine oxidase/xanthine dehydrogenase inhibitor, for gout and hyperuricemia. Arthritis Rheum, 48:S530.

Kamatani N, Fujimori S, Hada T, et al. 2004. Febuxostat, a novel non-Purine selective inhibitor of xanthine oxidase, in an allopurinol-controlled phase III clinical trial in Japanese subjects with gout or hyperuricemia. Arthritis Rheum, 50:804/103.

Khosravan R, Grabowski BA, Mayer MD, et al. 2006a. The effect of mild and moderate hepatic impairment on pharmacokinetics, pharmacodynamics, and safety of febuxostat, a novel nonpurine selective inhibitor of xanthine oxidase. J Clin Pharmacol, 46:88-102.

Khosravan R, Grabowski BA, Wu JT, et al. 2006b. Pharmacokinetics, pharmacodynamics and safety of febuxostat, a non-purine selective inhibitor of xanthine oxidase, in a dose escalation study in healthy subjects. Clin Pharmacokinet, 45:821-41.

Khosravan R, Grabowski B, Wu JT, et al. 2008a. Effect of food or antacid on pharmacokinetics and pharmacodynamics of febuxostat in healthy subjects. Br J Clin Pharmacol, 65:355-63.

Khosravan R, Kukulka MJ, Wu JT, et al. 2008b. The effect of age and gender on pharmacokinetics, pharmacodynamics, and safety of febuxostat, a novel nonpurine selective inhibitor of xanthine oxidase. $J$ Clin Pharmacol, 48:1014-24.

Khosravan R, Mayer MD, Wu JT, et al. 2005a. Effect of concomitant administration of febuxostat and colchicine on pharmacokinetics of febuxostat and colchicine at steady state. Arthritis Rheum, 52(suppl): S102-3.

Khosravan R, Wu JT, Joseph-Ridge N, et al. 2006c. Pharmacokinetic interactions of concomitant administration of febuxostat and NSAIDs. J Clin Pharmacol, 46:855-66.
Khosravan RP, Erdman KB, Vernillet LPP, et al. 2005b. Effect of febuxostat on pharmacokinetics of desipramine, a CYP2D6 substrate, in healthy subjects. Clin Pharmacol Ther, 77:P43, PI-137.

Kim KY, Ralph Schumacher H, Hunsche E, et al. 2003. A literature review of the epidemiology and treatment of acute gout. Clin Ther, 25:1593-617.

Komoriya K, Hoshide S, Takeda K, et al. 2003. Pharmacokinetics and pharmacodynamics of febuxostat (TMX-67), a non-purine selective inhibitor of xanthine oxidase/xanthine dehydrogenase (NPSIXO) in patients with gout and/or hyperuricemia. Nucleosides Nucleotides Nucleic Acids, 23:1119-22.

Komoriya K, Hoshide S, Takeda K, et al. 2004. Pharmacokinetics and pharmacodynamics of febuxostat (TMX-67), a non-purine selective inhibitor of xanthine oxidase/xanthine dehydrogenase (NPSIXO) in patients with gout and/or hyperuricemia. Nucleosides Nucleotides Nucleic Acids, 23:1119-22.

Komoriya K, Osada Y, Hasegawa M, et al. 1993. Hypouricemic effect of allopurinol and the novel xanthine oxidase inhibitor TEI-6720 in chimpanzees. Eur J Pharmacol, 250:455-60.

Krishnan E, Baker JF, Furst DE, et al. 2006. Gout and the risk of acute myocardial infarction. Arthritis Rheum, 54:2688-96.

Li-Yu J, Clayburne G, Sieck M, et al. 2001. Treatment of chronic gout. Can we determine when urate stores are depleted enough to prevent attacks of gout? J Rheumatol, 28:577-80.

Mayer MD, Khosravan R, Vernillet L, et al. 2005. Pharmacokinetics and pharmacodynamics of febuxostat, a new non-purine selective inhibitor of xanthine oxidase in subjects with renal impairment. Am $J$ Ther, $12: 22-34$.

Mukoyoshi M, Nishimura S, Hoshide S, et al. 2008. In vitro drug-drug interaction studies with febuxostat, a novel non-purine selective inhibitor of xanthine oxidase: plasma protein binding, identification of metabolic enzymes and cytochrome P450 inhibition. Xenobiotica, 38:496-510.

Okamoto K, Eger BT, Nishino T, et al. 2003. An extremely potent inhibitor of xanthine oxidoreductase. Crystal structure of the enzyme-inhibitor complex and mechanism of inhibition. J Biol Chem, 278:1848-55.

Okamoto K Nishino T. 2008. Crystal structures of mammalian xanthine oxidoreductase bound with various inhibitors: allopurinol, febuxostat, and FYX-051. J Nippon Med Sch, 75:2-3.

Osada Y, Tsuchimoto M, Fukushima H, et al. 1993. Hypouricemic effect of the novel xanthine oxidase inhibitor, TEI-6720, in rodents. Eur J Pharmacol, 241:183-8.

Roddy E, Zhang W Doherty M. 2007. The changing epidemiology of gout. Nat Clin Pract Rheumatol, 3:443-9.

Sanchez-Lozada LG, Tapia E, Bautista-Garcia P, et al. 2008a. Effects of febuxostat on metabolic and renal alterations in rats with fructose-induced metabolic syndrome. Am J Physiol Renal Physiol, 294:F710-8.

Sanchez-Lozada LG, Tapia E, Soto V, et al. 2008b. Effect of febuxostat on the progression of renal disease in 5/6 nephrectomy rats with and without hyperuricemia. Nephron Physiol, 108:69-78.

Sanchez-Lozada LG, Tapia E, Soto V, et al. 2008c. Treatment with the xanthine oxidase inhibitor febuxostat lowers uric acid and alleviates systemic and glomerular hypertension in experimental hyperuricaemia. Nephrol Dial Transplant, 23:1179-85.

Schlesinger N. 2004. Management of acute and chronic gouty arthritis: present state-of-the-art. Drugs, 64:2399-416.

Schumacher HR Jr, Becker MA, Wortmann RL, et al. 2006. The FOCUS trial 48-month interim analysis: long-term clinical outcomes of treatment with febuxostat in subjects with gout in an ongoing phase 2, open-label extension study. ACR/ARHP Annual Scientific Meeting.

Schumacher HR, Jr. Becker MA, Wortmann RL, et al. 2005. Febuxostat vs allopurinol and placebo in subjects with hyperuricemia and gout: the 28-week APEX study. Arthritis Rheum, 52:S680.

Schumacher HR, Jr. Wortmann R, Becker MA, et al. 2004. A phase 2, long term open-label safety and efficacy study of febuxostat, a novel non-purine, selective inhibitor of xanthine oxidase. Arthritis Rheum, $50: 800 / 180$. 
Slot O. 1994. [Hyperuricemia]. Ugeskr Laeger, 156:2396-401.

Takano Y, Hase-Aoki K, Horiuchi H, et al. 2005. Selectivity of febuxostat, a novel non-purine inhibitor of xanthine oxidase/xanthine dehydrogenase. Life Sci, 76:1835-47.

Teng GG, Nair R, Saag KG. 2006. Pathophysiology, clinical presentation and treatment of gout. Drugs, 66:1547-63.

Tomlinson B. 2005. Febuxostat (Teijin/Ipsen/TAP). Curr Opin Investig Drugs, 6:1168-78.

Wortmann R, Becker MA, Schumacher HR Jr, et al. 2004. Gout flare prophylaxis during management of chronic gout with febuxostat, a non-purine selective inhibitor of xanthine oxidase. Arthritis Rheum, 50:801/103.
Wortmann RL. 2002. Gout and hyperuricemia. Curr Opin Rheumatol, 14:281-6.

Wortmann RL. 2005. Recent advances in the management of gout and hyperuricemia. Curr Opin Rheumatol, 17:319-24.

Wortmann RL, Becker MA, Schumacher HR Jr, et al. 2006. Effect of febuxostat or allopurinol on the clinical manifestations of gout: reduction in gout flares and tophus size over time in the EXCEL trial. ACR/ARHP Annual Scientific Meeting.

Zhao L, Roche BM, Wessale JL, et al. 2008. Chronic xanthine oxidase inhibition following myocardial infarction in rabbits: effects of early versus delayed treatment. Life Sci, 82:495-502. 